\title{
"Um homem pra chamar de seu": discurso musical e construção de gênero
}

\author{
Alvaro Neder (IFRJ, Rio de Janeiro, RJ) \\ alvaroneder@ig.com.br
}

\begin{abstract}
Resumo: Este artigo examina o gênero musical como discurso do coletivo anônimo. Por esta via, a música participa poderosamente das construções de gênero e também das contestações a estas construções, por parte de grupos sociais anti-hegemônicos. Considerando-se as conotações socialmente atribuidas a certos subgêneros do rock, são analisadas as estratégias de contestação feminina às posições atribuídas às mulheres por meio da apropriação de papeis de dominação exercidos tradicionalmente por homens. Tais estratégias são iluminadas pelo confronto entre as interpretações de Marina Lima e Erasmo Carlos para Mesmo que seja eu, canção de Roberto Carlos e Erasmo Carlos. Relativizando a noção de autonomia autoral, o artigo subscreve a perspectiva pós-estruturalista de que os artistas são, eles próprios, discursos de um coletivo, e conclui considerando o papel da música, enquanto discurso social, na produção de novas subjetividades e na reestruturação da ordem social.
\end{abstract}

Palavras-chave: discurso musical e gênero; subjetividade e crítica cultural; pós-estruturalismo na música.

\section{"A man to call yours": musical discourse and gendering}

Abstract: This article examines musical genre as an anonymous collectivity's discourse. According to this understanding, music powerfully participates in gendering and its contestations by non-hegemonic social groups. Considering socially attached connotations to certain rock subgenres, feminine challenge strategies to the positions assigned to women are implemented through women's appropriation of roles traditionally performed by men. Such procedures are illuminated by the confrontation of Brazilian singers Marina Lima and Erasmo Carlos' renderings for Mesmo que seja eu [Even if it's me], a song by Roberto Carlos and Erasmo Carlos. Relativizing the notion of authorial autonomy, the article subscribes to the poststructuralist perspective that the artists themselves are discourses of a collectivity, and concludes with a consideration of the role of music as a social discourse in the production of new subjectivities, and in the restructuring of social order.

Keywords: musical discourse and gendering; subjectivity and cultural criticism; poststructuralism in music.

\section{1 - Introdução}

0 campo midiático, entendido como o conjunto de diferentes mediações estabelecidas entre as produções culturais e seus fruidores pelos meios de comunicação de massa, vem sendo objeto de um diferente olhar, nas últimas décadas. Sob o impacto dos chamados estudos culturais, começou-se a perceber que os sujeitos expostos à ação destes meios - tanto na ponta da produção como da recepção - produzem estratégias de oposição e resistência que complexificam e problematizam os significados das produções veiculadas pelos mass media. Vistos por este ângulo, os meios de comunicação de massa passam a representar um outro espaço que se oferece para a atividade de contestação, e para a produção de sujeitos críticos.
No terreno específico da canção popular brasileira, o estruturalismo subsidiou análises especificas das letras das canções desde os anos 1970 (ver, por exemplo, SILVA, 1974). No entanto, este tipo de abordagem cedo encontrou suas limitações. As letras não são textos verbais, mas sequências sonoras vocais linguisticamente marcadas, e que são mediadas por convenções musicais, como diz o musicólogo Richard MIDDLETON $(2000$, p.7). Isto é, diferentes gêneros musicais e estilos de performance musical modificam os sentidos veiculados pelo mesmo texto linguístico, como veremos no decorrer deste artigo. Portanto, a análise dos sentidos veiculados pela canção coloca o problema metodológico de esses sentidos constituírem-se em um composto indissociável de letra, música, performance e contexto cultural mais amplo. 
Se estamos falando da participação da canção na construção identitária de sujeitos críticos, é inevitável voltarmos nossa atenção para a desafiadora questão do sentido dos sons musicais. Se, como foi dito, as convenções musicais modificam até mesmo o sentido dos textos verbais, de que maneira isto se dá? Há muitas possibilidades de responder a esta pergunta. Aqui, vamos nos ater à ideia de discurso musical.

\section{2 - Gênero musical e discurso}

0 nivel codal (nivel de um código em uma estrutura de códigos) pertinente aos nossos propósitos, neste artigo, será o do gênero musical. Segundo concepções musicológicas contemporâneas, o gênero deixou de ser definido exclusivamente por suas características formais, e seu entendimento passou a orientar-se

em direção a uma concepção mais fluida e flexivel, preocupada, acima de tudo, com a função, com a retórica ou "discurso" do gênero no interior da comunicação e recepção da arte. As unidades de repetição que definem um gênero musical [...] podem estender-se para o domínio social, de tal forma que a definição de um gênero dependerá do contexto, função e validação pela comunidade, e não, simplesmente, em regulação formal e técnica. Assim, as repetições estariam localizadas em dominios sociais, comportamentais e mesmo ideológicos, bem como em materiais musicais. (SAMSON, 2005)

Ainda, conforme lembra Samson, o gênero possui uma função de estabilização de significados - uma função socialmente conservadora, que deve ser mantida em mente.

Por sua vez, o etnomusicólogo Robert Walser desenvolveu estudos sobre o gênero musical baseando-se nos trabalhos em teoria literária de Tzvetan Todorov. Para WALSER (1993, p.xiv), o gênero musical deixa de ser compreendido como um conjunto autônomo de características estilístico-formais, e passa a constituirse em um sistema social de produção e comunicação de sentidos. Os detalhes musicais dos gêneros tornam-se um discurso - "unidades gestuais e sintáticas significantes, organizadas por narrativas e outras convenções formais, [que] constituem um sistema para a produção social de sentido" (WALSER, 1993, p.xiv).

Se os gêneros musicais são sistemas de significação social - discursos, como afirma Walser - então os indivíduos podem identificar-se com tais discursos, e isto é de fácil verificação. Muito frequentemente, a profunda apreciação por um gênero - o rap, o punk rock, o samba, o pagode - é acompanhada pela adoção, pelo sujeito, de códigos sartoriais, comportamentais e linguísticos associados a estes gêneros. Isto quer dizer que, sendo um discurso, o gênero musical conecta a subjetividade aos processos sócio-históricos. Desta maneira, gêneros musicais conferem identidades. Detalhes musicais passam a associar-se a atitudes e crenças - ideologias - que tanto congregam comunidades de sujeitos identificados com os valores do grupo, como também mantêm afastados aqueles que adotam uma atitude de rejeição em relação a estes valores.
No entanto, uma vez estabelecidos significados para os elementos estilísticos, surge também a possibilidade de apropriação diferencial, "anômala" ou crítica, destes mesmos detalhes musicais, por parte de outros grupos, levando à sua ressignificação, notadamente, através do jogo e da ironia. Evidentemente, estes novos significados adicionados aos gêneros participam, por sua vez, do complexo processo de produção de subjetividades por meio da música, ao tornarem-se objeto de identificações por parte dos fruidores.

A este ponto, coloca-se a necessidade de problematizar a habitual tendência de negligenciar a participação do coletivo anônimo na criação das produções culturais. $\mathrm{Ou}$ seja, o fato de que certos elementos estilístico-musicais adquirem conotações que os fazem ser incorporados a gêneros musicais com fortes associações existenciais parece dever-se a escolhas, negociações, conflitos e disputas coletivos, mais do que a decisões autônomas emanadas de cantores, compositores e instrumentistas profissionais. Pelo contrário, parece legítimo acreditar que estes artistas devem seu sucesso eventual à felicidade com que captam, com sua intuição privilegiada, tais conflitos e opções coletivas.

Esta abordagem se insere na linhagem pós-estruturalista que interpreta a cultura como um texto, inaugurada pelo crítico literário Silviano Santiago no Brasil em 1972, no artigo "Caetano Veloso enquanto Superastro" (SANTIAGO, 2000, p.148). Neste artigo, inicialmente, Santiago chama a atenção para a cobertura jornalística dos astros de cinema pela imprensa estadunidense da década de 50 para discutir o fato de que essas revistas buscavam construir uma imagem dos artistas que fosse condizente com 0 "critério estabelecido pela verdade da comunidade, isto é, [com o] código de comportamento e de valores ditado pela middle class americana e que as revistas reafirmavam, ou pelo elogio ou pela crítica, ao homem ou ao ator" (SANTIAG0, 2000, p.147). Em outras palavras, a ideologia social, da qual as revistas eram representantes, construia os artistas. Através das revistas, a ideologia estabelecia que era necessário "[t]irar a maquiagem do rosto do homem para poder the entregar a responsabilidade do cidadão atuante dentro da comunidade" (SANTIAGO, 2000, p.147). Confundir a ambas poderia ser perigoso, sugere Silviano. 0 astro é, então, não um valor positivo, mas um significado construído relacionalmente a partir de categorias simbólicas sociais: um discurso. Portanto, da mesma forma que o discurso musical do gênero, o artista é um discurso: a sociedade fala por intermédio de seus artistas.

Sendoassim, metodologicamente, esteartigoacompanhará o pensamento de autores que advogam que uma canção (música, letra, performance) é uma representação da comunidade e do nativo. Tão confiável quanto qualquer outra, não invalida, mas não é substituível pelo caderno de campo e outras formas de registro etnográfico mais estabelecidas. 0 etnomusicólogo Steven Feld (FELD, 1990), por exemplo, busca entender através dos textos 
(ou seja, músicas) como os nativos reais escutam e pensam sobre suas atividades, e musicólogos como Susan McClary (MCCLARY, 1991) e Christopher Small (cf. seu conceito de musicar, SMALL, 1987 e 1999) compreendem estruturas musicais como textos fabricados socialmente cujo cerne são construções históricas e políticas. Mais ainda, de maneira geral, este foco na música "em si" como elemento iluminador da integralidade de uma cultura é a própria razão de ser de campos de estudo como um todo, como a etnomusicologia (que possui um foco decididamente antropológico) e os popular music studies. Já há algumas décadas, parte da musicologia também se

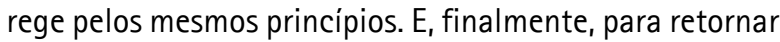
à perspectiva pós-estruturalista, o "texto" em si não se distingue do "contexto", pois é formado de fragmentos da ideologia (que perpassa a realidade cotidiana, e não se distingue da cultura, em seu sentido antropológico). A experiência se constrói nesse texto mais amplo escrito pela cultura (ou ideologia), sendo impossivel "sair" do texto (isto é, das estruturas simbólicas que perpassam/ constroem a cultura, as instituições, os modos de produção e os textos musicais discretos). Por esta razão, a ilusão de que os textos musicais (supostamente fantasiosos e irreais) são separados de uma "realidade" palpável e concreta constitui-se em uma oposição metafísica. Pelo mesmo movimento, compreende-se que o papel da música na construção de subjetividades não deriva de uma consciência supostamente transcendental (o Autor), mas de uma atividade produtiva - embora, desde sempre, contraditória - do coletivo anônimo.

\section{3 - Discursos musicais conservadores e transgressões femininas}

0 objetivo deste ensaio é, então, estudar de que maneira a cantora e compositora Marina Lima - enquanto discurso de um coletivo - se apropriou das convenções (socialmente criadas) de gênero do rock, com o fim de problematizar e ironizar construções de gênero na canção Mesmo que seja eu (Roberto Carlos/Erasmo Carlos). Este processo é consequente da atividade produtiva do coletivo anônimo, como descrito anteriormente, e retroage sobre os processos de subjetivação de seus ouvintes, realimentando o processo.

0 estilo de Marina - longe de ser uma criação inteiramente individual - já evidencia, por si, este mecanismo coletivo de subjetivação descrito acima, uma vez que a cantora insere-se em uma linhagem de mulheres que desafiaram a hegemonia masculina ao apropriarem-se de atributos simbólicos reservados aos homens. No caso em questão, estilos de emissão vocal, escolha de repertório, códigos sartoriais e gestuais, e outras decisões socialmente marcadas em relação aos gêneros feminino e masculino. Esta linhagem de mulheres transgressoras inclui, de forma mais radical, Bessie Smith e Janis Joplin, entre outras.

A música popular anglo-saxônica é especialmente pertinente aqui, pelo fato de constituir-se no depositório musical e cultural privilegiado por Marina Lima para a montagem de seu estilo. 0 timbre característico da voz cantada de Janis Joplin, por exemplo, foi tomado do gênero conhecido nos países anglo-saxões como "cock" rock. Conforme os críticos Simon Frith e Angela McRobbie, o "cock" rock é "uma expressão explícita, crua e frequentemente agressiva da sexualidade masculina" (FRITH e McROBBIE, 1990, p.374). A voz neste estilo consiste em um som áspero, que é frequentemente utilizado por cantores como Bruce Springsteen, Rod Stewart e Mick Jagger. 0 som é produzido essencialmente pela garganta e pela boca, com uma utilização mínima das câmaras de ressonância do peito e da cabeça, e através de uma forte tensão das cordas vocais (SHEPHERD, 1991, p.167).

Para Frith e McRobbie, "cock" rockers têm a propensão de serem "agressivos, dominadores, fanfarrões, e buscam, constantemente, lembrar suas plateias de seus poderes e seu controle" (FRITH e McROBBIE, 1990, p.374). Ao apropriar-se destas convenções músico-culturais, Janis assumiu a posição simbólica de um homem sendo uma mulher, estabelecendo um olhar irônico em relação aos papéis definidos estereotipicamente para os gêneros. Ao mesmo tempo em que desconstruía definições essencialistas de homem e mulher, Janis reclamava também para o gênero feminino prerrogativas reservadas ao gênero masculino, abrindo a possibilidade de avanços sociais e políticos concretos e significativos. Possibilidade retomada, entre outras cantoras famosas e mulheres comuns (cantarolando em suas tarefas cotidianas), por Marina Lima, explicitando o caráter social e coletivo deste poderoso mecanismo de subjetivação proporcionado pela música em sua especificidade.

0 soft rock é um gênero complementar ao "cock" rock. Trata-se de um gênero baseado na sentimentalidade da forma balada, tradicional no repertório anglo-saxão, e que se coloca - estereotipicamente - no plano do "feminino". A complementaridade entre "cock" rock e soft rock na fabricação dos gêneros masculino e feminino se dá entre dois momentos de um mesmo homem (agressivo/vulnerável) e de uma mesma mulher (objeto da agressividade masculina, e entidade maternal provedora de afeto e compreensão). Mas não se deve esquecer a complementaridade entre homens e mulheres a ocupar posições simbióticas concretas ao longo deste eixo simbólico imposto pela ordem social e reproduzido pela música. Isto é, a uma masculinidade agressiva corresponde uma feminilidade submissa, e assim por diante.

Como veremos, Mesmo que seja eu, na interpretação de Marina, desestabiliza e torna ambíguas as convenções dos gêneros musicais empregados. Para TODOROV (1990, p.10), os gêneros literários encarnam as ideologias de uma sociedade, e o mesmo pode ser dito dos gêneros musicais, como vimos. Portanto, a sobrevivência das ideologias apóia-se em sua presença definida e entendida sem ambiguidades no interior das produções simbólicas desta sociedade. Logo, pode-se supor o que poderia acontecer caso estas definições tornassem-se consistentemente 
confusas e indefinidas - em outras palavras, caso o que acontece, no plano particular, com Mesmo que seja eu, se tornasse generalizado.

Segundo FRITH E McROBBIE (1990, p.375-381), o soft rock oferece três posições discursivas definidas para identificação por parte de ouvintes e performers: 1) a jovem solteira ou esposa que usa seus encantos e empatia para atrair e apoiar emocionalmente o homem vulnerável; 2) o jovem rapaz vulnerável, envolvido em seus problemas de afirmação na adolescência; e 3) a mulher como objeto sexual. A estes eixos temáticos correspondem timbres definidos, que estabelecem a identidade musical do soft rock, assim como vimos no caso do "cock" rock. Para Shepherd, o som típico de uma cantora identificada com a primeira posição ("woman as nurturer", ou figura maternal) é suave e cálido, produzido com as pregas vocais mais relaxadas; utilizando em particular a câmara peitoral, produz um som rico e ressonante. No segundo caso, do qual um bom exemplo é "Yesterday", cantada por Paul McCartney, a voz do cantor é também quente e suave, em comparação com o som áspero e rígido do "cock" rock, mas aquelas qualidades são atingidas menos com a ressonância peitoral do que com as câmaras da cabeça. 0 som é, portanto, leve e fino, comparado com aquele obtido pela mulher enquanto figura maternal. Analogamente, os sons da mulher-objeto são sensivelmente mais tensos e brilhantes, e tendem a ressoar na cabeça (SHEPHERD, 1991, p.167-168).

\section{4 - Mesmo que seja eu: intertextualidade e contradição em duas interpretações conflitantes}

Com base nestas considerações sobre detalhes musicais e suas significações convencionais em nossa cultura, passemos à análise de Mesmo que seja eu, inicialmente na interpretação de Marina Lima e, em seguida, comparando-a à versão de Erasmo Carlos. A intertextualidade resultante deste procedimento, inclusive, parece ter sido proposta deliberadamente pela cantora, uma vez que suas intenções críticas e irônicas se tornam mais evidentes a partir do exame comparativo das duas versões. Sendo largamente conhecida, a gravação de Erasmo Carlos para esta canção não coloca problemas para seu reconhecimento e confronto para os ouvintes que entraram em contato com a interpretação de Marina.

Musicalmente, uma textura extremamente leve é produzida na introdução por um acompanhamento monofônico em pizzicato utilizando a fundamental e a quinta, com uma figura em ostinato que comunica um pulso energético sutil. A esta linha melódica vem juntar-se uma outra linha contrapontística, que utiliza um timbre de piano elétrico. 0 todo transmite a ideia de indefinição e expectativa, e se adapta bem à ideia de uma atmosfera sexualizada que se confirmará com as primeiras palavras emitidas pela cantora, ocupando a posição de mulher-objeto.
Na versão de Marina Lima, percebemos uma deliberada ambiguidade entre os variados campos semânticos atualizados pelas retóricas dos gêneros "cock" rock e soft rock, que é potencializada pelos significados veiculados pelo texto linguístico. Neste momento da introdução, a cantora faz sua primeira intervenção adotando o papel da mulher que se oferece ao olhar de desejo masculino, ao sussurrar com voz rouca palavras que sugerem 0 encontro erótico (0:08-0:15min). No entanto, a frase dita, "é... cada um de nós precisa... precisa de um homem... pra chamar de seu..." já provoca um certo estranhamento no ouvinte, por perturbar a lógica convencional que rege a flexão de gênero do artigo indefinido em relação ao sujeito da enunciação. Será que a cantora está a dizer (ao ouvinte, identificado com a posição de parceiro/ parceira) que todos precisamos de um homem, inclusive os homens? Mas que definição de homem seria válida neste caso, já que o sujeito da enunciação é uma mulher que se anunciará como um homem no refrão da canção, ainda que através de locução conjuntiva concessiva ("mesmo que seja eu...")?

Nos momentos iniciais de sua intervenção cantada (0:22-0:54) Marina continua adotando a posição de objeto do desejo do observador, ainda que a emissão vocal, em certos pontos, seja colorida pelo sarcasmo ("desilusão, meu bem..."; "xi..."). Em um dado momento, a cantora adota momentaneamente as convenções vocais do "cock" rock, fazendo a transposição mulher-objeto/ macho desejante ("xi, sem ninguém!", 0:56), retornando em seguida à posição inicial. Seguirá nesta postura sexualmente provocante até bem próximo do final da canção (3:38), quando, então, adota definitivamente 0 timbre tomado ao "cock" rock, utilizando o qual repetirá várias vezes "um homem pra chamar de seu/ mesmo que seja eu". A ironia é evidente ao nível linguístico, por tratarse ela de um sujeito do gênero feminino; mas é ainda potencializada pelo timbre marcado pela agressividade sexual masculina. Esta ambiguidade definida pela voz feminina em contraste com a posição simbólica masculina é ainda complexificada pela decisão de manter o acompanhamento instrumental no gênero soft rock. Desestabilizando as convenções de gênero através de um jogo irônico levado a efeito por meio do discurso musical, Marina define seu intuito crítico. Propósito que se torna ainda mais visível se compararmos sua interpretação para esta canção com a de Erasmo Carlos, o letrista de Mesmo que seja eu. Aqui temos oportunidade de perceber como a performance e a execução musical - enunciação - são suficientes para transformar os sentidos do texto verbal (enunciado).

Ouvindo agora esta outra versão, que na verdade antecedeu cronologicamente a de Marina, podemos perceber ainda mais claramente a intenção irônica da cantora, visto que ela interpela explicitamente a versão de Erasmo. Nesta, o cantor epitomiza o gênero soft rock. Sua voz, tímida e insegura, situa-se no extremo oposto à autoconfiança arrogante do "cock" rock, e explicita sua vulnerabilidade 
ao dirigir-se à mulher desejada. Não ouvimos aqui ironia ou sarcasmo, mas uma busca de "autenticidade". 0 cantor tem consciência de sua inadequação ao papel masculino socialmente validado, e sua narrativa assume 0 tom desencantado de quem faz uma oferta sexual que se sabe insatisfatória, mas que ao menos é real (uma concepção de real amparada no plano biológico, na falta de uma efetiva capacidade de empatizar com o outro, partilhar problemas e proporcionar apoio emocional e afetivo).

Esta confissão de fracasso é salientada pela cadência interrompida, que coincide exatamente com o eu no refrão ("mesmo que seja eu...", 2:43). Com suas conotações de incompletude, carência, desapontamento enfim, a cadência interrompida, coincidindo com o eu, equivale a uma confissão de impotência, neste contexto. É importante ressaltar também que a cadência interrompida ocorre em três outras situações que se referem à situação de desamparo da mulher a quem o cantor se dirige: "sozinha (no silêncio do seu quarto"), "(jamais vai poder livrar você da fera da) solidão" e "(aumen)ta o rádio". Através deste recurso semiótico musical, estabelece-se uma relação de identidade entre o homem e a mulher, que é fundada na fraqueza, na penúria (de amor e de recursos para superar as adversidades). Este instante musical é coerente com a ideia geral que o cantor comunica a respeito da mulher decantada. Quando se refere às fantasias fracassadas da interlocutora, a seus castelos, dragões e desilusões, percebemos um tom claramente condoído. 0 sujeito da enunciação se identifica com a mulher, colocada também em posição de fragilidade pela frustração do próprio desejo dela. Assim, a figura feminina deixa de ter interesse como objeto sexual. Seu sofrimento - na imaginação do rapaz que canta - a tira da posição de objeto de desejo, e ela passa a ocupar na psique dele o lugar de uma entidade maternal, capaz de proporcionar compreensão e aceitação de suas fraquezas, de sua inadequação. Deve-se notar que, em ambas as posições, a mulher não é sentida ou experienciada como parceira.

Entendemos, agora, com mais sutileza a interpretação de Marina. Com sua ironia e sarcasmo, a cantora coloca o "real" em questão. Enquanto a persona construída por Erasmo se apresenta como um candidato ao amor que, mesmo usufruindo de uma condição biológica masculina, se desculpa antecipadamente por sua insuficiência como homem, a criação de Marina impõe-se, com humor, de forma inteiramente afirmativa. Em sua versão, Marina praticamente exclui a cadência interrompida, que surge apenas duas vezes, e mesmo assim apenas no início da canção. Na primeira ocorrência (0:44), é resignificada por meio do sarcasmo ("xi..."). Na segunda (1:23), pelo uso de um forte tensionamento rítmico, que dominará o restante da música. A partir daí, a cadência interrompida é substituída pela cadência perfeita. Na versão de Marina, a voz que ouvimos não é condescendente, não se condói de sua interlocutora e nem de si mesma, e portanto pode prescindir dos recursos da cadência interrompida. Seu sarcasmo é como um puxão de orelhas afetuoso, que subentende a convicção de que a interpelada tem plenas reservas para reagir à desilusão e retornar à vida por si mesma.

Na boca de Marina, "mesmo que seja eu" não é confissão de inadequação, mas constatação brincalhona de um desmoronamento das categorias de "homem" e "mulher" tal como estão instituidas. Na intertextualidade construída pelas duas versões, o homem "real" significado por Erasmo é fraco e impotente, enquanto o homem construído ironicamente por Marina é seguro e autoconfiante, e vê em sua parceira estas mesmas características.

E que homem seria este? Retornando ao início, que definição de homem seria válida neste caso? Frente ao fracasso e impotência do homem "real", e à autoconfiança do homem incorporado pelo sujeito da enunciação interpretado por Marina, as definições convencionais perdem a consistência - o que parece real deixa de sê-lo, e o resultado é a instabilidade (das identidades e categorias "masculino" e "feminino"). A partir de então, é impossivel para nós deixarmos de associar estas ideias transgressoras ao discurso musical instituído, o que introduz uma fissura na rigidez semiótica do gênero musical. Participando da produção de novas subjetividades, este discurso encontra sua expressão mais ampla na reestruturação da ordem social. Contribuindo para desestabilizar o discurso identitário desde sua fundação - a ordem simbólica - através da subversão do discurso musical, o discurso social de muitas mulheres que antecederam Marina Lima e é retomado por ela faz a crônica de tempos diferentes e inscreve sua fala no diálogo com o Mesmo. 


\section{Referências}

FELD, Steven. Sound and sentiment: birds, weeping, poetics, and song in Kaluli expression. Philadelphia: University of Pennsylvania Press, 2a ed., 1990.

FRITH, Simon; McROBBIE, Angela. Rock and Sexuality. In: FRITH, S.; GOODWIN, A. (eds.). On record. Rock, pop and the written word. New York: Pantheon, 1990.

HOLLANDA, Chico Buarque de. Chico Buarque de Hollanda, v.1. Texto de contracapa. [LP] RGE $3030003,1966$.

McCLARY, Susan. Feminine endings: music, gender, sexuality. Minneapolis: University of Minnesota Press, 1991.

MIDDLETON, Richard. Introduction: Locating the Popular Music Text. In: Richard Middleton (ed.). Reading pop: approaches to textual analysis in popular music. New York: Oxford UP, 2000.

SAMSON, Jim. Genre. In: L. Macy (Ed.). Grove Music Online. Disponível em <http://www.grovemusic.com> (Acesso em 23 de Outubro, 2005).

SANTIAGO, Silviano. Caetano Veloso enquanto Superastro. In: Uma literatura nos trópicos. 2a ed. Rio de Janeiro: Rocco, 2000, p.143-163.

SHEPHERD, John. Music as social text. Cambridge: Polity Press, 1991.

SILVA, Anazildo Vasconcelos da. A poética de Chico Buarque: a expressão subjetiva como fundamento da significação. Rio de Janeiro: Sophos Editora, 1974.

SMALL, Christopher. El musicar: un ritual en el Espacio Social. In: Transcultural Music Review 4. Disponível em <http://www.sibetrans.com/trans/trans4/small.htm> (Acesso em 4 de Maio, 2007), 1999.

Music of the common tongue: survival and celebration in Afro-American music. New York: Riverrun, 1987.

TODOROV, Tzvetan. Genres in discourse. Tradução Catherine Porter. Cambridge: Cambridge UP, 1990. Título original: Genres du discours.

WALSER, Robert. Running with the devil: power, gender, and madness in heavy metal music. Hanover, NH: University Press of New England, 1993.

Álvaro Simões Corrêa Neder é etno/musicólogo e professor da graduação e pós-graduação do Instituto Federal de Educação, Ciência e Tecnologia do Rio de Janeiro (IFRJ). Possui Doutorado em Música, pela UNIRIO (2012), e Doutorado Multidisciplinar em Letras (Literatura Brasileira, Linguagem e Teoria da Literatura) pela PUC-Rio (2007). Foi Teacher Assistant na Universidade Brown durante parte de seu estágio de doutoramento nesta universidade, ministrando o curso Introduction to Ethnomusicology. Publicou o livro Creativity in Education: Can Schools Learn with the Jazz Experience? (WCP, EUA, 2002). Sua tese de doutorado sobre a MPB dos anos 60 foi selecionada pelo Programa de Pós-Graduação em Letras da PUC-Rio para representar o programa no Grande Prêmio Nacional Capes de Teses de Doutorado 2008. Como crítico musical, publicou textos para vários livros de referência lançados nos EUA e acima de 2.300 artigos na imprensa norte-americana. Desde 1980 atua como professor de música, músico e produtor musical, tendo sido membro da Old Time String Band, coordenada pelo etnomusicólogo Jeff Titon. 